\title{
Smoker's characteristics, general health and their perception of smoking in the social environment: a study of smokers in Rajshahi City, Bangladesh
}

\author{
Md. Kamruzzaman ${ }^{1}$ (D) - Ahammad Hossain ${ }^{2}$ - Enamul Kabir ${ }^{3}$ \\ Received: 29 July 2020 / Accepted: 17 November 2020 / Published online: 6 January 2021 \\ (C) Springer-Verlag GmbH Germany, part of Springer Nature 2021
}

\begin{abstract}
Background Smoking is one of the bad habits in social environment and is one of the main causes of immature death in Bangladesh. Rajshahi is one of the cleanest, most peaceful cities in Bangladesh, but the inhabitants often feel uncomfortable about smokers who smoke in public places and often on transport. Smoking frequency is very high among males compared to females, and a large number of smokers are building or road construction laborers and people involved in offering different services such as transportation, vending from vans, etc. The practice of smoking in this area is destructive for mental and physical health especially for students compared to other professionals because the city is known as the City of Education.

Methods The study analyzes smokers' characteristics, general health, and their (smokers) perception of smoking in public places. Cross-sectional data were collected randomly from 160 smokers through face-to-face questionnaire survey. The determinants of complexities with regard to social environment and human health were studied using frequency distribution, chi-square test, and binary and multinomial logistic regression analysis using IBM SPSS version 24.

Results Frequency distributions reveal that $93.8 \%$ of smokers believe that smoking creates public health hazards, $51.3 \%$ of smokers think it causes breathing complexities for non-smokers, $48.8 \%$ of smokers feel smoking causes air pollution, $68.8 \%$ of smokers think smoking causes gastric problems, $24.4 \%$ of smokers had headache problems due to smoking and cigarette fumes, $86.3 \%$ of smokers learnt smoking from friends, $48.8 \%$ of smokers smoke due to their addiction and $25.6 \%$ for depression, and $80.6 \%$ usually smoke after having a meal. The chi-square test reveals that class of smokers was significantly associated with frequency of heartbeat rate, starting smoking at specific age level was significantly associated with suffering from diseases, category of smoking articles was significantly associated with suffering from disease, class of smokers was significantly associated with causes for smoking, and starting smoking at specific age level was significantly associated with profession of the smokers at $1 \%$ level of significance respectively. A significant odds ratio was found $(\mathrm{OR}=6.363,95 \% \mathrm{CI} 1.918-21.104$, $p<0.01$ ) for the profession group of students/labour at $1 \%$ level; their outcomes for suffering from diseases such as gastric problem and fever/headache/others were 6.363 times those for the profession group of service/other smokers.

Conclusion Smoking in public places should be restricted because non-smokers cannot breathe freely and it is not healthy for them to inhale smoke indirectly, which has many adverse effects on public health. The study also reveals that the majority of the smokers have gastric problems, abnormal heartbeat rates, frequent headaches, depression and addiction problems, etc., and that they believe that smoking causes significant health hazard on human health and social environment. Therefore, necessary interventions should be taken immediately by policy-makers to prevent smoking in public places.
\end{abstract}

Keywords Smoker's characteristics $\cdot$ General health hazards $\cdot$ Social environment $\cdot$ Bangladesh

Md. Kamruzzaman

mkzaman@ru.ac.bd

Ahammad Hossain

ahammadstartru@gmail.com

Enamul Kabir

Enamul.Kabir@usq.edu.au
Institute of Bangladesh Studies, University of Rajshahi, Rajshahi, Bangladesh

2 Department of CSE, Varendra University, Rajshahi, Bangladesh

3 School of Sciences, University of Southern Queensland, Toowoomba, Australia 


\section{Introduction}

Social environment refers to the direct physical and social surroundings in which people live. The social environment includes the groups to which we belong to, including the geographic neighborhood (Yen and Syme 1999). Public health is the science and art of avoiding disease, prolonging life, and supporting health through planned efforts and effective adaptations of health-beneficial policies by society, organizations, communities, and individuals as a whole. In this particular research, it is concerned and with all sorts of threats to health resulting from the practice of smoking in public places. Smoking is a global practice in which substances, most commonly tobacco, are burned and the smoke is inhaled and exhaled. In Bangladesh, the common form of smoking is cigarettes, bidis (small, thin, hand-rolled cigarettes) and marijuana smoking. An e-cigarette is an electronic device that simulates tobacco smoking. It consists of an atomizer, power source (battery), and a container (cartridge or tank). Instead of smoke, the user inhales vapor (Cheng 2014). E-cigarette users have been increasing exponentially across the globe (Schraufnagel et al. 2014). In 2011, there were about 7 million adult ecigarette smokers globally, rising to 41 million in 2018 (Jones 2019). E-cigarettes are not publicly available in Bangladesh. Recently, the Bangladesh government plans to prohibit the sale and use of e-cigarettes amid growing health concerns (Dhaka Tribune 2019). From our survey study, none of the respondents inhale e-cigarettes in the city of Rajshahi. So this study excluded the prevalence of E-cigarettes, but included cigarettes, bidis and marijuana smoking. Once people start smoking, they usually have a hard time quitting (Jarvis 2004). This is due to the addictive chemical nicotine, a main ingredient in tobacco (Fiore et al. 1996; Rothemich et al. 2008). Nicotine dependence arises when you react to nicotine and cannot stop without using it. Nicotine produces pleasing effects in the brain, but these effects are temporary (Bellows et al. 2007). So you reach for more tobacco (cigarette/bidis). The more you smoke, the more nicotine you need to feel good (Rothemich et al. 2008). When smokers try to stop, they feel unpleasant mentally and physically (Picciotto and Kenny 2013; Mayo Clinic 2020). Thus, smoking turns into an addiction. About 1.1 billion people smoke worldwide, which is expected to rise to more than 1.6 billion by 2025 (World Bank 1999; Busg et al. 2003). There are recent reports in the research literature that environmental degradation is associated with diseases and mortality risks (independent of individual risk factors) because of smoking (Yen and Syme 1999; Ockene and Miller 1997; Sadeghi et al. 2011). These findings investigate how smoking influences disease pathways in the social environment. Worldwide tobacco-related deaths were 4.83 million in 2000 and 6.4 million in 2015, and are estimated to reach 8.3 million in 2030 (Ezzati and Lopez 2004). Deaths attributable to smoking are projected to increase substantially throughout the 21 st century, and much of the increase will occur in low- and middle-income countries such as Bangladesh, whose population of 150 million makes it the seventh most populous country in the world (Jha 2009). In the low- and middle-income countries, tobacco-related deaths were 3.4 million in 2002 and are estimated to increase to 6.8 million in 2030 (Mathers and Loncar 2006; Bush et al. 2003). Tobacco-related illnesses accounted for $16 \%$ of total deaths among the general population of Bangladesh whose age is 30 years and above (World Health Organization 2005; Bush et al. 2003). Tobacco-use prevalence significantly decreased among adults from $43.3 \%$ in 2009 to $35.3 \%$ in 2017 (from $58.0 \%$ to $46.0 \%$ among males; from $28.7 \%$ to $25.2 \%$ among females). This represents an $18.5 \%$ relative decline of tobacco use (20.8\% decline for males; $12.2 \%$ decline for females) (GATS 2017). There are about 1.5 million adults suffering from tobacco-attributable illness in Bangladesh (Faruque et al. 2019). Tobacco killed nearly 126,000 people in Bangladesh in 2018, accounting for $13.5 \%$ of all deaths in the country (Faruque et al. 2019). More than 61,000 children (below age 15) are suffering from diseases caused by exposure to secondhand smoke (Faruque et al. 2019). Over a quarter of Bangladeshi adult smokers (5.0\% of adults overall) consume bidis (GYTS 2013). Among youth (ages 13-15), 6.9\% use tobacco in some form (boys 9.2\%; girls 2.8\%) (GYTS 2013). Of all adults above age $15,35.3 \%$ use tobacco products; among men the percentage is $46.0 \%$, among women $25.2 \%$ (GYTS 2017). Eighteen percent smoke tobacco (men $36.2 \%$ and women $0.8 \%$ ); $20.6 \%$ of adults use smokeless tobacco (men 16.2\% and women 24.8\%) (GYTS 2017). However, much remains to be learned about the impact on public health due to smoking in the social environment. A study projected diabetes by logistic regression and machine learning algorithms based on the National Health and Nutrition Examination Survey 2009-2012. Their model demonstrated that seven factors out of 14 (age, education, BMI, systolic BP, diastolic BP, direct cholesterol, and total cholesterol) are the risk factors for diabetes (Maniruzzaman et al. 2020). A cross-sectional study survey was undertaken on students which examined the new phenomena of energy drinks based on the participants' personnel characteristics, university grade, and the impact on health status. This showed that a serious concern exists for the health and safety of the mostat-risk students who engaged in daily energy drink usage; two-thirds of these reported difficulties sleeping, more than one experienced heart palpitation and blood pressure; onethird had anxiety, nervousness, and feeling thirsty; and one fifth indicated tiredness and headache (Dwaidy et al. 2018). Smoking causes death, and more deaths are reported to be caused each year by tobacco use than by human immunodeficiency virus (HIV). Recent research shows that if people stopped smoking, one in three deaths due to cancer would not happen in the USA (U.S. Department of Health and 
Human Services Report 2010). Smoking increases health risks compared to non-smokers. It is estimated to increase the threat of coronary heart diseases by 2 to 4 times, strokes by 2 to 4 times, and dying from chronic obstructive lung diseases by 12 to 13 times, the leading cause of death in the USA (Mokdad et al. 2004; U.S. Department of Health and Human Services Report 2004; Thompson et al. 2003). Cigarette smoking causes obstruction of the normal circulation of blood by narrowing the blood vessels, which puts smokers at high risk of rising peripheral vascular disease (Giudice et al. 2012). Smoking causes lung diseases by damaging the airways and alveoli of the lungs and also creates respiratory diseases such as lung cancer (Wang et al. 2018; Cai et al. 2020). Smoking has created many adverse effects on reproductive health, including the increased risk for infertility, preterm delivery, stillbirth, low birth weight and sudden infant death syndrome (SIDS) (Vogt et al. 2008; Ezzati et al. 2002; U.S. Department of Health and Human Services Report 2020). A study was conducted for understanding the influences of smoking behavior in Bangladeshi and Pakistani adults based on gender, age, religion, and tradition. Peer pressure was an important influence on smoking behavior in younger people, who tend to hide their smoking from elders. Tradition, culture, and the family played an important role in nurturing and cultivating norms and values around smoking (Bush et al. 2003). An epidemiological study was designed to determine the prevalence and risk factors of cigarette smoking behavior among 600 Rajshahi University male students in Bangladesh. The prevalence of cigarette smoking behavior among university students was $9.5 \%$. The $\chi^{2}$-test demonstrated that monthly family income $(p<0.01)$, fathers' smoking status $(p<0.01)$, brother(s)/uncles' smoking status $(p<0.01)$ were significantly associated with students' cigarette smoking behavior (Mamun et al. 2018). In a recent study, a statistically significant association was found between smoking status and SARS-CoV-2 (Simons et al. 2020). Another study was conducted to understand the comparison between the smoking behavior and attitudes of smokers who strongly believe in smoking-related problems with those who do not believe. A total of $83.8 \%$ (2955/3525) of people in Pakistan completed the questionnaire, and $34.7 \%$ were smokers. Another study performed multiple logistic regression where smokers perceived that their problems were smoking related, and they were more likely to have tried stopping in the past [odds ratio (OR) $1.78,95 \%$ confidence interval (CI) 1.26-2.67, to want to stop smoking $(\mathrm{OR}=1.83$, CI 1.15-2.9) or to intend to stop in the near future ( $\mathrm{OR}=1.58$, CI 1.03-2.43) (Coleman et al. 2003). Prevalence and correlation of smoking have been analyzed using secondary data from the 2006 Urban Health Survey (UHS), which was conducted among adult men of six city corporations in Bangladesh considering slum versus nonslum residents. The authors reported higher rates of smoking cigarettes and bidis in slums as compared to men living in the urban non-slums (Khan et al. 2009). So far as we can identify, no study has been conducted to investigate smokers' general health and their thoughts on how smoking affects the social environment in one of the cleanest cities in Bangladesh. So, it is important to investigate smokers' characteristics and general health, and the effect of smoking on social environment in the area.

\section{Methods and materials}

The study covers Rajshahi City, which is situated in northern Bangladesh. There are 30 wards in the city area; wards are less-developed parts of the entire city infrastructure, where there is a low literacy rate and there is more accessibility to smoking items such as like bidis, marijuana (local name ganja), cigarettes, and various drugs, in particular phensedyl. The total population of the city area is 449,756, of whom 232,974 are male and 216,782 female, with a sex ratio (M/F) of 107.469 and a population density per square kilometer of 4318 (Bangladesh Bureau of Statistics 2013).

To choose survey questionnaires, relevant studies were reviewed. After the literature reviewed in the Introduction section above was taken into account, we prepares openended questionnaires. Pre-testing interviews were conducted to check the adequacy of the responses among the respondents compared to the data of relevant studies. Finally, we prepared a closed-ended questionnaire based on pre-testing interviews. The exact number of the smoker population is unknown because there is no existing study conducted on smokers in the area. The sample size was calculated by the following formula (Survey system 2020) for unknown population.

The required sample size, $n=\frac{Z^{2} \times P \times(1-P)}{C^{2}}=160$

Where, $Z=Z$ value (1.96 for $95 \%$ confidence level), $\mathrm{P}=$ percentage picking a choice $(0.5$ used for maximum sample taken), and $\mathrm{C}=$ margin of error $(0.0775= \pm 7.75)$. Among 30 wards, three wards, namely ward-7, ward-10, and ward-20, were selected randomly using simple random sampling procedure. The study was based on cross-sectional design study, and the required data were collected through face-to-face interview with a pretested questionnaire. The total 160 respondents (male 130 and female 30) who are addicted to smoking were selected randomly from the three selected wards. Statistical analyses were performed using IBM SPSS version 24. Frequency distribution was used to compute the characteristics of smokers and their opinion of smoking on social environment and public health (Marmot and Wilkinson 2006). The main null hypothesis - there is no significant association between smoking attributes and general health or social attributes (bivariate association) — was checked using 
$\chi 2$ test between the following pairs of variables: frequency of heartbeat rate and class of smokers, suffering from diseases and started smoking at age level in years, category of smoking articles and suffering from diseases, gender and class of smokers, class of smokers and wards of the smokers, causes for smoking and class of smokers, from which person smoking was learned and started smoking at age level in year, and profession of the smokers and started smoking at age level in year. The null hypothesis was tested by chisquare test to test the association between two variables, and the null hypothesis was rejected if the $p$ value of the test statistic was less than $0.01(p<0.01)$ at $1 \%$ level of significance and $0.05(p<0.05)$ at $5 \%$ level of significance (Diener 2008; Mosteller 1968). Binary logistic regression (Islam et al. 2020; Coleman et al. 2003) was estimated considering 'suffering from diseases during smoking' as the dependent variable, and the independent variables to be educational qualification, ward, age group, gender, profession, frequency of smoking related to meal time, BMI class, and from which person did you learn smoking? Multinomial logistic regression was also applied to determine which factors best explain and predict health characteristics of smokers, general health, and their perception of smoking outcome. The significant odds ratios (OR) are found if the $p$ value of the test statistic was less than $0.01(p<0.01)$ at $1 \%$ level of significance and $0.05(p<0.05)$ at $5 \%$ level of significance (Chakraborty et al. 2003; Wahed and Hassan 2017).

\section{Results and discussion}

The demographic characteristics of smokers are shown in Table 1. There were 130 male respondents $(81.3 \%)$ and 30 female respondents $(18.8 \%)$. The profession of the respondents was student 18 (11.3\%), labor 73 (45.6\%), and service $69(43.1 \%)$. The age level of the respondents in years was seven below 15 (4.4\%), 25 in between 15 to below 25 (15.6\%), 73 in between 25 to below 35 (45.6\%), 49 in between 35 to below 45 (30.6\%), and six above 45 (3.80\%). The mean and SD age for the respondents were 41.797 and 0.511 years respectively.

Table 2 shows that the great majority $(93.8 \%)$ of the smokers believe that smoking has an impact on the social environment, while $6.3 \%$ believe that it does not: $48.8 \%$ of smokers feel that smoking cause air pollution, and $51.3 \%$ also feel that smoking has an impact on the breathing of nonsmokers (passive smoking).

Table 3 shows that the majority of respondents (113, $70.6 \%)$ smoke bidis, 38 (23.8\%) smoke low-price cigarettes, seven $(4.4 \%)$ smoke high-price cigarettes, and two (1.3\%) smoke other things (including marijuana). The smoker respondents suffer from various diseases such as gastric problems $(110,68.8 \%)$, fever $(11,6.9 \%)$, and headache $(39$,
Table 1 Demographic characteristics of the respondents of the study area

\begin{tabular}{|c|c|c|c|c|c|}
\hline \multirow[t]{2}{*}{ Variables } & \multicolumn{2}{|l|}{ Total } & \multirow[t]{2}{*}{ Variables } & \multicolumn{2}{|c|}{ Total } \\
\hline & $N$ & $\%$ & & $N$ & $\%$ \\
\hline \multicolumn{3}{|l|}{ Wards } & \multicolumn{3}{|l|}{ Gender } \\
\hline Ward-7 & 55 & 34.4 & Male & 130 & 81.3 \\
\hline Ward-10 & 55 & 34.4 & Female & 30 & 18.8 \\
\hline Ward-20 & 50 & 31.3 & Total & 160 & 100 \\
\hline \multirow[t]{2}{*}{ Total } & 160 & 100.0 & & & \\
\hline & & & \multicolumn{3}{|l|}{ Age } \\
\hline \multicolumn{3}{|c|}{ Respondent's profession } & Below 15 & 7 & 4.4 \\
\hline Student & 18 & 11.3 & 15 to below 25 & 25 & 15.6 \\
\hline Labor & 73 & 45.6 & 25 to below 35 & 73 & 45.6 \\
\hline Service & 69 & 43.1 & 35 to below 45 & 49 & 30.6 \\
\hline \multirow[t]{2}{*}{ Total } & 160 & 100.0 & 45 plus & 6 & 3.80 \\
\hline & & & Total & 160 & 100 \\
\hline
\end{tabular}

Source: Researchers' own field survey

24.4\%). The smoker respondents learnt to smoke at below 10 years old $(51.3 \%)$. Mainly, they learnt 'second-hand smoking' by collecting bidis or cigarettes thrown away by smokers, and they sometimes learnt smoking from their older friends aged 10 to 15 (25\%) or 15 plus (23.8\%). The mean and SD age of learning smoking among the respondents were 11.894 and 3.442 years respectively. The frequency of smoking in relation to meal time was as follows: 15 of respondent smokers (9.4\%) smoked before meals, 129 (80.6\%) smoked after meals, $12(7.5 \%)$ smoked at any time and four $(2.5 \%)$ smoked at any other convenient time. At the time of smoking, 160 (100\%) smokers felt an effect on heartbeats, such as low heartbeat rate $(40,25 \%)$, high heartbeat rate $(113,70.6 \%)$, and other effects (seven, $4.4 \%)$. Out of 160 smokers, $82(51.3 \%)$ were chain smokers (chain smoking is the practice of smoking several bidis or cigarettes in succession, sometimes using the ember of a finished cigarette to light the next). The term chain smoker often also refers to a person who smokes relatively constantly, though not necessarily chaining each bidi or cigarette. Of the rest, 38 (23.8\%) smoked sometimes and $40(25 \%)$ smoked more than three times a day. The smokers smoke for various reasons such as being addicted $(78,48.8 \%)$, depressed $(41,25.6 \%)$, influence of friends $(38,23.8 \%)$ and other reasons (three, $1.9 \%)$. The smokers were asked "from which person did you learn smoking?": $86.3 \%$ of smokers learnt smoking from friends, $2.5 \%$ from fathers, $8.1 \%$ from brothers, and $3.1 \%$ from others, as shown in Fig. 1.

The testing of the null hypothesis - that there is no association between smoking and a series of variables - was tested using the following pairs of variables: frequency of heartbeat rate and class of smokers, suffering from diseases 
Table 2 Frequency distribution of the respondents about the impacts of smoking on social environment

\begin{tabular}{|c|c|c|c|c|c|}
\hline \multirow[t]{2}{*}{ Variables } & \multicolumn{2}{|c|}{ Total } & \multirow{2}{*}{ Variables } & \multicolumn{2}{|c|}{ Total } \\
\hline & $-N$ & $\%$ & & $-N$ & $\%$ \\
\hline \multicolumn{3}{|c|}{ Smoking has an impact on the social environment } & \multicolumn{3}{|l|}{ Types of impact } \\
\hline Yes & 150 & 93.8 & Air pollution & 78 & 48.8 \\
\hline No & 10 & 6.3 & Breathing impact on non-smokers & 82 & 51.3 \\
\hline Total & 160 & 100.0 & Total & 160 & 100.0 \\
\hline
\end{tabular}

Source: Researchers' own field survey and started smoking at age level in years, category of smoking articles and suffering from diseases, gender and class of smokers, class of smokers and wards of the smokers, causes of smoking and class of smokers, from which person smoking was learned and started smoking at age level in year, and profession of the smokers and started smoking at age level in year. The cross tables of smoking attributes with $\chi^{2}$ test statistics and $p$ value are presented in Table 4 .

As seen from Table 4, the results are described in the following manner. Class of smokers are significantly associated with effects on heartbeats $\left(\chi^{2}=160, p<0.01\right)$. The smokers who smoked more than three times $(100 \%)$ were more likely to have a low heartbeat than chain smokers and occasional smokers; on the other hand, chain smokers (68.3\%) and occasional smokers (31.7\%) were more likely to have high/other heartbeats. Started smoking at age level in year was significantly associated with suffering from diseases $\left(\chi^{2}=104.603\right.$, $p<0.01)$. The smokers who were below 10 years old $(70.0 \%)$ or above 15 years $(30.0 \%)$ were likely to have gastric problems; on the other hand, $80.0 \%$ of smokers who were at age
Table 3 Frequency distribution of the respondents with regard to the perception on human health hazards

\begin{tabular}{|c|c|c|c|c|c|}
\hline \multirow[t]{2}{*}{ Variables } & \multicolumn{2}{|l|}{ Total } & \multirow[t]{2}{*}{ Variables } & \multicolumn{2}{|c|}{ Total } \\
\hline & $N$ & $\%$ & & $N$ & $\%$ \\
\hline \multicolumn{3}{|l|}{ Categories of smoking articles } & \multicolumn{3}{|l|}{ Effect on heartbeats } \\
\hline Bidis & 113 & 70.6 & Yes & 160 & 100 \\
\hline Low-price cigarettes & 38 & 23.8 & No & 0 & 0 \\
\hline High-price cigarettes & 7 & 4.4 & Total & 160 & 100 \\
\hline Others (Including marijuana) & 2 & 1.3 & & & \\
\hline \multirow[t]{2}{*}{ Total } & \multirow[t]{2}{*}{160} & \multirow[t]{2}{*}{100} & Frequency of heartbeat rate & & \\
\hline & & & Low & 40 & 25 \\
\hline \multicolumn{3}{|l|}{ Suffering from diseases } & High & 113 & 70.6 \\
\hline Gastric problem & 110 & 68.8 & Others & 7 & 4.4 \\
\hline Fever & 11 & 6.9 & Total & 160 & 100 \\
\hline Headache & 39 & 24.4 & & & \\
\hline \multirow[t]{2}{*}{ Total } & \multirow[t]{2}{*}{160} & \multirow[t]{2}{*}{100} & Class of smoker & & \\
\hline & & & Chain smoker & 82 & 51.3 \\
\hline \multicolumn{3}{|c|}{ Started smoking at age level in year } & Smoke sometimes & 38 & 23.8 \\
\hline Below 10 & 82 & 51.3 & More than three times per day & 40 & 25 \\
\hline 10 to 15 & 40 & 25.0 & Total & 160 & 100 \\
\hline 15 plus & 38 & 23.8 & & & \\
\hline \multirow[t]{2}{*}{ Total } & \multirow[t]{2}{*}{160} & \multirow[t]{2}{*}{100} & Causes of smoking & & \\
\hline & & & Addiction & 78 & 48.8 \\
\hline \multicolumn{3}{|c|}{ Frequency of smoking related to meal time } & Depression & 41 & 25.6 \\
\hline Before meals & 15 & 9.4 & Influence of friends & 38 & 23.8 \\
\hline After meals & 129 & 80.6 & Others & 3 & 1.9 \\
\hline Any time & 12 & 7.5 & Total & 160 & 100 \\
\hline Others & 4 & 2.5 & & & \\
\hline Total & 160 & 100 & & & \\
\hline
\end{tabular}

Source: Researchers' own field study 


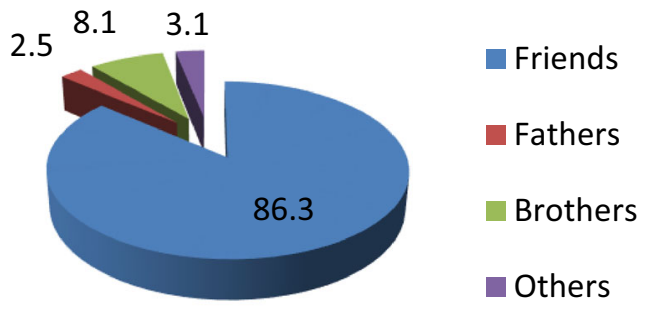

Fig. 1 Pie-chart of the person from whom respondents learnt smoking

10-15 were likely to have fever/headache/other diseases. Category of smoking articles was significantly associated with suffering from diseases $\left(\chi^{2}=104.603, p<0.01\right)$. The smokers who smoked bidis $(95.5 \%)$ were more likely to suffer from gastric problems; on the other hand, smokers who smoked low-price cigarettes/high price cigarettes/others (84.0\%) were more likely suffering from fever/headache/other diseases. Class of smokers was not significantly associated with gender of smokers $\left(\chi^{2}=1.396, p>0.01\right)$. Class of smokers was not significantly associated with ward of smokers $\left(\chi^{2}=0.107\right.$, $p>0.01)$. Class of smokers was significantly associated with causes for smoking $\left(\chi^{2}=289.356, p<0.01\right)$. The smokers who were chain smokers $(100 \%)$ were more likely to have addiction to smoking; the smokers who smoked more than three times in a day $(95.1 \%)$ were more likely to have depression; and the smokers who smoked sometimes $(92.7 \%)$ were more likely to have been influenced by friends/others. Started smoking at age level in year was not significantly associated with from which person did you learn smoking $\left(\chi^{2}=2.092\right.$, $p>0.01)$. Started smoking at age level in year was significantly associated with profession of smokers $\left(\chi^{2}=40.553\right.$, $p<0.01)$. The smokers who started smoking at age $10_{-}$ 15 years $(44.0 \%)$ were more likely to be from the profession student/labour; the smokers who started smoking at age below $10(37.4 \%)$ were more likely to be from the profession student/labour; and the smokers who started smoking at age level below $10(69.6 \%)$ were more likely to be service/other profession holders.

In the above section, bivariate analysis of smokers' characteristics, general health, and perception of smoking in the social environment, categorized as predisposing and enabling factors, was performed to examine the nature of the association between these factors and smoking exposure status. Numerous associations were found to be significant in the bivariate analysis. However, bivariate association between two variables using $\chi^{2}$ test does not necessarily imply a significant causal relationship between them. Therefore, binary and multinomial logistic regression was applied to determine which factors best explain and predict smokers' health characteristics, general health, and perception of smoking outcome. For binary logistic regression, suffering from diseases during smoking was considered as the dependent variable, with outcomes gastric problems $(68 \%)$ and fever/headache/other $(31.3 \%)$, and independent variables such as education qualification, ward, age group, gender, profession, frequency of smoking related to meal time, BMI class and 'from which person did you learn smoking?' were considered as categorical covariates. Table 5 shows the frequency distribution of required variables for binary logistic regression estimation, and Table 6 shows the estimated results of binary logistic regression of suffering from diseases during smoking on categorical covariates including $p$ value, odds ratio (OR) and 95\% CI for OR.

As seen in Table 6, the results are interpreted in the following ways. The OR of smoking learnt from friends is $(\mathrm{OR}=$ $2.630,95 \%$ CI $0.739-9.355, p>0.01)$. The smokers who learnt smoking from friends were more likely to suffer from diseases compared to smokers who learnt smoking from father/brothers/others, although this is not statistically significant. It is evident that smokers who learnt smoking from friends were 2.630 times more likely to suffer from diseases compared to smokers who learnt smoking from father/ brothers/others. The ORs of age at below 15/15 to below 25, and 25 to below 35 are $\mathrm{OR}=2.630,95 \%$ CI $0.739-9.355$, $p>0.01$ and $\mathrm{OR}=1.739,95 \%$ CI $0.460-6.576, p>0.01$ respectively. Younger smokers were more likely to suffer from diseases compared to older smokers, although ORs were not statistically significant. It is evident that smokers below 25 years of age were 2.275 times more likely to suffer from disease compared to the smokers of age 35 and above, and smokers below 35 years of age were 1.739 times more likely to suffer from disease compared to smokers of age 35 and above. The OR for the male gender was OR $=0.804,95 \%$ CI $0.286-2.266, p>0.01$, which is not statistically significant. The OR of profession of students/labours was $\mathrm{OR}=6.363$, 95\% CI 1.918-21.104, $p<0.01$. Student/labour smokers were more likely to suffer from diseases compared to service/other smokers; the difference was statistically significant. It was shown that student/labour smokers are 6.363 times more likely to suffer from diseases compared to service/other smokers. The OR of smoking before meal time was OR $=1.280,95 \%$ CI $0.329-4.973, p>0.01$. The smokers who smoked before meal time were more likely to suffer from diseases compared to smokers who smoked after meal/any time/others, although this was not statistically significant. It was shown that smokers who smoked before meal time were 6.363 times more likely to suffer from diseases compared to smokers who smoked after meal/any time/other. The OR of overweight/obese smokers was $\mathrm{OR}=1.130,95 \%$ CI 0.517-2.471, $p>0.01$. Overweight/obese smokers were more likely to suffer from diseases compared to underweight/normal weight smokers, although this was not statistically significant. It was shown that overweight/obese smokers were 1.130 times more likely to suffer from diseases compared to underweight/normal 
Table 4 The cross tables of smoking attributes with $\chi^{2}$ test statistics and $p$ value

\begin{tabular}{|c|c|c|c|c|c|c|c|}
\hline \multirow{2}{*}{\multicolumn{2}{|c|}{ Frequency of heartbeat rate vs class of smokers }} & \multicolumn{4}{|c|}{ Class of smokers } & \multicolumn{2}{|c|}{ Test statistics } \\
\hline & & Chain smoker & $\begin{array}{l}\text { Smokes } \\
\text { sometimes }\end{array}$ & More than three times per day & Row total & $x^{2}$ & $P$ value \\
\hline \multirow[t]{2}{*}{ Frequency of heartbeat rate $(\%)$} & Low & 0 & 0 & 100 & 25 & $160.00^{\mathrm{a}}$ & 0.000 \\
\hline & High/others & 68.3 & 31.7 & 0 & 75 & & \\
\hline \multirow{2}{*}{\multicolumn{2}{|c|}{$\begin{array}{l}\text { Suffering from diseases vs started smoking at age level in } \\
\text { year }\end{array}$}} & \multicolumn{4}{|c|}{ Started smoking at age level in year } & \multirow{4}{*}{$\begin{array}{l}\chi^{2} \\
117.936^{\mathrm{a}}\end{array}$} & \multirow{4}{*}{$\begin{array}{l}P \text { value } \\
0.000\end{array}$} \\
\hline & & Below 10 & $10-15$ & Above 15 & Row total & & \\
\hline \multirow[t]{2}{*}{ Suffering from diseases $(\%)$} & Gastric problem & 70 & 0 & 30 & 68.8 & & \\
\hline & Fever/headache/others & 10 & 80 & 10 & 31.3 & & \\
\hline \multirow{2}{*}{\multicolumn{2}{|c|}{ Category of smoking particles vs suffering from diseases }} & \multicolumn{4}{|c|}{ Category of smoking articles } & \multirow{4}{*}{$\begin{array}{l}\chi^{2} \\
104.603^{\mathrm{a}}\end{array}$} & \multirow{4}{*}{$\begin{array}{l}P \text { value } \\
0.000\end{array}$} \\
\hline & & Bidis & Low-price cigarettes & /high-price cigarettes/others & Row total & & \\
\hline \multirow[t]{2}{*}{ Suffering from diseases $(\%)$} & Gastric problem & 95.5 & 4.5 & & 68.8 & & \\
\hline & Fever/headache/others & 16 & 84 & & 31.3 & & \\
\hline \multirow{2}{*}{\multicolumn{2}{|c|}{ Gender vs class of smokers }} & Class of smok & & & & \multirow{2}{*}{$\begin{array}{l}\chi^{2} \\
1.396\end{array}$} & \multirow{2}{*}{$\begin{array}{l}P \text { value } \\
0.498\end{array}$} \\
\hline & & Chain smoker & $\begin{array}{l}\text { Smokes } \\
\text { sometimes }\end{array}$ & More than three times per day & Row total & & \\
\hline \multirow[t]{2}{*}{ Gender $(\%)$} & Male & 52.3 & 24.6 & 23.1 & 81.3 & & \\
\hline & Female & 46.7 & 20 & 33.3 & 18.8 & & \\
\hline \multirow{2}{*}{\multicolumn{2}{|c|}{ Class of smokers vs wards of the smokers }} & \multicolumn{4}{|c|}{ Class of smokers } & \multirow{5}{*}{$\begin{array}{l}\chi^{2} \\
0.107\end{array}$} & \multirow{5}{*}{$\begin{array}{l}P \text { value } \\
0.999\end{array}$} \\
\hline & & Chain smoker & $\begin{array}{l}\text { Smokes } \\
\text { sometimes }\end{array}$ & More than three times per day & Row total & & \\
\hline \multirow[t]{3}{*}{ Wards $(\%)$} & Ward-7 & 52.7 & 23.6 & 23.6 & 34.4 & & \\
\hline & Ward-10 & 50.9 & 23.6 & 25.5 & 34.4 & & \\
\hline & Ward-20 & 50.0 & 24 & 26 & 31.3 & & \\
\hline \multirow{2}{*}{\multicolumn{2}{|c|}{ Causes of smoking vs class of smokers }} & \multicolumn{4}{|c|}{ Class of smokers } & \multirow{5}{*}{$\begin{array}{l}\chi^{2} \\
289.356^{\mathrm{a}}\end{array}$} & \multirow{5}{*}{$\begin{array}{l}P \text { value } \\
0.000\end{array}$} \\
\hline & & Chain smoker & $\begin{array}{l}\text { Smokes } \\
\text { sometimes }\end{array}$ & More than three times per day & Row total & & \\
\hline \multirow[t]{3}{*}{ Causes of smoking $(\%)$} & Addiction & 100 & 0 & 0 & 48.8 & & \\
\hline & Depression & 4.9 & 0 & 95.1 & 25.6 & & \\
\hline & Influence of friends/others & 4.9 & 92.7 & 2.4 & 25.6 & & \\
\hline From which person did you lear & n smoking? vs started & Started smokin & ig at age level in year & & & & $P$ value \\
\hline smoking at age level in year & & Below 10 & $10-15$ & Above 15 & Row total & 2.092 & 0.351 \\
\hline Learnt smoking from (\%) & Friends & 49.3 & 26.8 & 23.9 & 86.3 & & \\
\hline & Father/brothers/others & 63.6 & 13.6 & 22.7 & 13.8 & & \\
\hline Profession of the smokers vs star & rted smoking at age level in & Started smokin & g at age level in year & & & & $P$ value \\
\hline year & & Below 10 & $10-15$ & Above 15 & Row total & $40.553^{\mathrm{a}}$ & 0.000 \\
\hline Profession $(\%)$ & Student/ labour & 37.4 & 44 & 18.7 & 56.9 & & \\
\hline & Service/others & 69.6 & 0.0 & 30.4 & 43.1 & & \\
\hline
\end{tabular}

All the cell frequencies are given in raw percentage, and raw totals are given in percentage of grand total. Although some of the cell frequencies were 0 , all the expected frequencies were greater than 5 and $^{\mathrm{a}}(p<0.01)$ indicates significant at $1 \%$ level

weight smokers. The ORs of ward-7 and ward-10 were OR $=$ $0.335,95 \%$ CI $0.088-1.279, p>0.01$ and $\mathrm{OR}=0.936,95 \%$ CI $0.223-3.937, p>0.01$ respectively; this was not statistically significant. The ORs of Illiterate and primary qualified smokers were $\mathrm{OR}=0.821,95 \%$ CI $0.212-3.180, p>0.01$ and $\mathrm{OR}=1.665,95 \%$ CI $0.477-5.808, p>0.01$ respectively. Smokers with a primary educational qualification were more likely to suffer from diseases compared to SSC/HSC/graduate/Masters qualified smokers, although this was not statistically significant. It was shown that primary qualified smokers were 1.665 times more likely to suffer from diseases compared to SSC/HSC/graduate/Masters qualified smokers.

Table 7 represents a case processing summary for multinomial logistic regression of cause for smoking with a view to corresponding categorical factors such as ward, age, gender, 'from which person did you learn smoking?', BMI class and profession. Table 8 represents estimation results of multinomial logistic regression (trichotomous) of cause for smoking (ref: addiction) with a view to corresponding categorical factors including $p$ value, Odds Ratio (OR) and $95 \%$ CI for OR.

In Table 8, the ORs are described in the following manner. The OR of underweight/normal weight smokers was OR= $1.060,95 \%$ CI $0.462-2.434, p>0.01$. Underweight/normal weight smokers were more likely to suffer from depression compared to overweight/obese smokers, although this was not statistically significant. It was shown that underweight/normal weight smokers were 1.060 times more likely to suffer from depression compared to overweight/obese smokers. The OR of learnt smoking from father/brothers/others was OR = $2.649,95 \%$ CI $0.698-10.060, p>0.01$. Smokers who learnt smoking from father/brothers/others were more likely to suffer from depression compared to smokers who learnt smoking from friends, although this was not statistically significant. It was shown that smokers who learnt smoking from father/ brothers/others were 2.649 times more likely to suffer from depression compared to smokers who learnt smoking from 
friends. The OR of smokers at age below $15 / 15$ to below 25 was $\mathrm{OR}=1.008,95 \%$ CI $0.260-3.907, p>0.01$. Smokers who were at age below $15 / 15$ to below 25 were more likely to suffer from depression compared to smokers of ages 35 and above, although this was not statistically significant. It was shown that smokers who were at age below $15 / 15$ to below 25 were 1.008 times more likely to suffer from depression compared to smokers of ages 35 and above. The OR of smokers at age 25 to below 35 was $\mathrm{OR}=0.848,95 \% \mathrm{CI}$ $0.209-3.436, p>0.01$. Smokers who were at age 25 to below 35 were less likely to suffer from depression compared to smokers of ages 35 and above, although this was not statistically significant. It was shown that smokers who were at age 25 to below 35 were 0.848 times less likely to suffer from depression compared to smokers of ages 35 and above. The OR of smokers from ward- 7 was OR $=1.259,95 \%$ CI 0.339 $4.670, p>0.01$. Smokers from ward-7 were more likely to suffer from depression compared to smokers from ward-20, although this was not statistically significant. It was shown that smokers from ward- 7 were 1.259 times more likely to suffer from depression compared to smokers from ward-20. The OR of smokers from ward-10 was OR $=1.095,95 \%$ CI $0.253-4.748, p>0.01$. Smokers from ward-10 were more likely to suffer from depression compared to smokers from ward-20, although this was not statistically significant. It was shown that smokers from ward-10 were 1.095 times more likely to suffer from depression compared to smokers from ward-20.

The OR of underweight/normal weight smokers was $\mathrm{OR}=$ $0.556,95 \%$ CI $0.251-1.235, p>0.01$. Underweight/normal weight smokers were less likely to smoke upon the impact of effects of friends/others compared to overweight/obese smokers, although it is not statistically significant. It was shown that underweight/normal weight smokers were 0.556 times less likely to smoke upon the impact of effects of friends/others compared to overweight/obese smokers. The OR of learnt smoking from father/brothers/others was OR = $1.119,95 \%$ CI $0.379-3.309, p>0.01$. The smokers who learnt smoking from father/brothers/others were more likely to smoke as a result of the influence of friends/others compared to smokers who learnt smoking from friends, although this was not statistically significant. It was shown that smokers who learnt smoking from father/brothers/others were 1.119 times more likely to smoke as a result of the influence of friends/others compared to smokers who learnt smoking from friends. The OR of smokers at age below $15 / 15$ to below 25 was OR $=0.423,95 \%$ CI $0.102-1.758, p>0.01$. The smokers who were at age below $15 / 15$ to below 25 were less likely to
Table 5 Frequency distribution of required variables for binary logistic regression estimation

\begin{tabular}{|c|c|c|c|}
\hline Dependent variable (dichotomous) & & $N$ & $\%$ \\
\hline \multirow[t]{3}{*}{ Suffering from diseases during smoking } & Gastric problem & 110 & 68.8 \\
\hline & Fever/headache/others & 50 & 31.3 \\
\hline & Total & 160 & 100.0 \\
\hline \multicolumn{4}{|l|}{ Categorical covariates (independent variable) } \\
\hline \multirow[t]{3}{*}{ Educational qualification } & Illiterate & 61 & 38.125 \\
\hline & Primary & 33 & 20.625 \\
\hline & $\mathrm{SSC} / \mathrm{HSC} /$ graduation/masters & 66 & 41.25 \\
\hline \multirow[t]{3}{*}{ Ward } & Ward-7 & 55 & 34.375 \\
\hline & Ward-10 & 55 & 34.375 \\
\hline & Ward-20 & 50 & 31.25 \\
\hline \multirow[t]{3}{*}{ Age group } & Below $15 / 15$ to below 25 & 32 & 20 \\
\hline & 25 to below 35 & 73 & 45.625 \\
\hline & 35 to below $45 / 45$ plus & 55 & 34.375 \\
\hline \multirow[t]{2}{*}{ Gender } & Male & 130 & 81.25 \\
\hline & Female & 30 & 18.75 \\
\hline \multirow[t]{2}{*}{ Profession } & Student/ labour & 91 & 56.875 \\
\hline & Service/others & 69 & 43.125 \\
\hline \multirow[t]{2}{*}{ Frequency of smoking related to meal time } & Before meal & 15 & 9.375 \\
\hline & After meal/Any time/others & 145 & 90.625 \\
\hline \multirow[t]{2}{*}{ BMI class } & Underweight/normal & 102 & 63.75 \\
\hline & Overweight/obese & 58 & 36.25 \\
\hline \multirow[t]{2}{*}{ From which person did you learn smoking? } & Friends & 138 & 86.25 \\
\hline & Father/brothers/others & 22 & 13.75 \\
\hline
\end{tabular}

BMI is calculated as per WHO classification (WHO Expert Consultation 2004) 
Table 6 Estimation results of binary logistic regression of suffering from diseases during smoke on categorical covariates

\begin{tabular}{|c|c|c|c|c|c|c|c|}
\hline \multicolumn{3}{|c|}{ Categorical covariates (independent variable) } & \multirow[t]{2}{*}{ Estimate } & \multirow[t]{2}{*}{$P$ value } & \multirow[t]{2}{*}{ OR } & \multicolumn{2}{|c|}{$95 \%$ C.I. for OR } \\
\hline & & & & & & Lower & Upper \\
\hline \multirow[t]{12}{*}{ Step 1} & $\begin{array}{l}\text { From which person did you learn smoking? } \\
\text { (ref: father/brothers/others) }\end{array}$ & Friends & 0.967 & 0.135 & 2.630 & 0.739 & 9.355 \\
\hline & \multirow[t]{2}{*}{ Age group (ref: 35 to below $45 / 45$ plus) } & Below $15 / 15$ to below 25 & 0.822 & 0.233 & 2.275 & 0.589 & 8.787 \\
\hline & & 25 to below 35 & 0.553 & 0.415 & 1.739 & 0.460 & 6.576 \\
\hline & Gender (ref: female) & Male & -0.218 & 0.680 & 0.804 & 0.286 & 2.266 \\
\hline & Profession (ref: service/others) & Students/labour & 1.850 & 0.002 & $6.363^{\mathrm{a}}$ & 1.918 & 21.104 \\
\hline & $\begin{array}{l}\text { Frequency of smoking related to meal time } \\
\quad \text { (ref: after meal/any time/others) }\end{array}$ & Before meal & 0.247 & 0.722 & 1.280 & 0.329 & 4.973 \\
\hline & BMI class (ref: underweight/normal) & Overweight/obese & 0.122 & 0.759 & 1.130 & 0.517 & 2.471 \\
\hline & \multirow[t]{2}{*}{ Ward (ref: ward-20) } & Ward-7 & -1.094 & 0.109 & 0.335 & 0.088 & 1.279 \\
\hline & & Ward-10 & -0.066 & 0.928 & 0.936 & 0.223 & 3.937 \\
\hline & \multirow{2}{*}{$\begin{array}{l}\text { Education qualification (Ref: SSC/HSC/ } \\
\text { graduation/masters) }\end{array}$} & Illiterate & -0.197 & 0.775 & 0.821 & 0.212 & 3.180 \\
\hline & & Primary & 0.510 & 0.424 & 1.665 & 0.477 & 5.808 \\
\hline & Constant & & -2.827 & 0.007 & $0.059^{\mathrm{a}}$ & & \\
\hline
\end{tabular}

Variable(s) entered on step 1 ; ref represents reference category and ${ }^{\mathrm{a}}(p<0.01)$ indicates significant at $1 \%$ level

smoke as a result of the influence of friends/others compared to smokers of ages 35 and above, although this was not statistically significant. It was shown that smokers who were at age below $15 / 15$ to below 25 were 0.423 times less likely to smoke as a result of the influence of friends/others compared to smokers of ages 35 and above. The OR of smokers at age 25 to below 35 was $\mathrm{OR}=0.473,95 \%$ CI $0.122-1.841$, $p>0.01$. Smokers who were at age 25 to below 35 were less
Table 7 Case processing summary for multinomial logistic regression

\begin{tabular}{|c|c|c|c|}
\hline Variables & Category & $N$ & Marginal percentage \\
\hline \multirow[t]{3}{*}{ Causes for smoking (latest status) } & Addiction & 78 & $48.8 \%$ \\
\hline & Depression & 41 & $25.6 \%$ \\
\hline & Influence of friends/others & 41 & $25.6 \%$ \\
\hline \multirow[t]{3}{*}{ Ward } & Ward-7 & 55 & $34.4 \%$ \\
\hline & Ward-10 & 55 & $34.4 \%$ \\
\hline & Ward-20 & 50 & $31.3 \%$ \\
\hline \multirow[t]{3}{*}{ Age group } & Below $15 / 15$ to below 25 & 32 & $20.0 \%$ \\
\hline & 25 to below 35 & 73 & $45.6 \%$ \\
\hline & 35 to below $45 / 45$ plus & 55 & $34.4 \%$ \\
\hline \multirow[t]{2}{*}{ Gender } & Male & 130 & $81.3 \%$ \\
\hline & Female & 30 & $18.8 \%$ \\
\hline \multirow[t]{2}{*}{ From which person did you learn smoking? } & friends & 138 & $86.3 \%$ \\
\hline & Father/brothers/others & 22 & $13.8 \%$ \\
\hline \multirow[t]{2}{*}{ BMI class } & Underweight/normal & 102 & $63.8 \%$ \\
\hline & Overweight/obese & 58 & $36.3 \%$ \\
\hline \multirow[t]{2}{*}{ Profession } & Student/labour & 91 & $56.9 \%$ \\
\hline & Service/other & 69 & $43.1 \%$ \\
\hline Valid & & 160 & $100.0 \%$ \\
\hline Missing & & 0 & \\
\hline Total & & 160 & \\
\hline Subpopulation & & $56^{\mathrm{a}}$ & \\
\hline
\end{tabular}

a The dependent variable has only one value observed in 32 subpopulations $(57.1 \%)$ 
Table 8 Estimate of parameters of multinomial logistic regression of causes for smoking with associated factors

\begin{tabular}{|c|c|c|c|c|c|c|c|}
\hline \multicolumn{3}{|c|}{ Causes for smoking (ref: addiction) } & \multirow[t]{2}{*}{ Estimate } & \multirow[t]{2}{*}{$P$ value } & \multirow[t]{2}{*}{ OR } & \multicolumn{2}{|l|}{$95 \% \mathrm{CI}$ for OR } \\
\hline & & & & & & Lower bound & Upper bound \\
\hline \multirow[t]{8}{*}{ Depression } & Constant & & -1.105 & 0.208 & & & \\
\hline & BMI class (ref: overweight/obese) & Underweight/normal & 0.058 & 0.891 & 1.060 & 0.462 & 2.434 \\
\hline & $\begin{array}{l}\text { From which person did you learn } \\
\text { smoking? (ref: friends) }\end{array}$ & Father/brothers/others & 0.974 & 0.152 & $2.649^{\mathrm{b}}$ & 0.698 & 10.060 \\
\hline & Age group (ref: 35 to below $45 / 45$ plus) & Below $15 / 15$ to below 25 & 0.008 & 0.991 & 1.008 & 0.260 & 3.907 \\
\hline & & 25 to below 35 & -0.165 & 0.817 & 0.848 & 0.209 & 3.436 \\
\hline & Ward (ref: ward-20) & Ward-7 & 0.230 & 0.731 & 1.259 & 0.339 & 4.670 \\
\hline & & Ward-10 & 0.091 & 0.903 & 1.095 & 0.253 & 4.748 \\
\hline & Gender (ref: female) & Male & -0.589 & 0.237 & $0.555^{\mathrm{b}}$ & 0.209 & 1.473 \\
\hline \multirow{8}{*}{$\begin{array}{l}\text { Influence from } \\
\text { friends/others }\end{array}$} & Intercept & & -0.081 & 0.916 & & & \\
\hline & BMI class (ref: overweight/obese) & Underweight/normal & -0.586 & 0.150 & $0.556^{\mathrm{b}}$ & 0.251 & 1.235 \\
\hline & $\begin{array}{l}\text { From which person did you learn } \\
\text { smoking? (ref: Friends) }\end{array}$ & Father/brothers/others & 0.113 & 0.839 & 1.119 & 0.379 & 3.309 \\
\hline & Age group (ref: 35 to below $45 / 45$ plus) & Below $15 / 15$ to below 25 & -0.860 & 0.237 & $0.423^{\mathrm{b}}$ & 0.102 & 1.758 \\
\hline & & 25 to below 35 & -0.748 & 0.281 & 0.473 & 0.122 & 1.841 \\
\hline & Ward (ref: ward-20) & Ward-7 & 0.827 & 0.209 & $2.286^{\mathrm{b}}$ & 0.629 & 8.312 \\
\hline & & Ward-10 & 0.699 & 0.366 & 2.013 & 0.441 & 9.180 \\
\hline & Gender (ref: female) & Male & -0.401 & 0.442 & 0.669 & 0.240 & 1.864 \\
\hline
\end{tabular}

${ }^{\mathrm{b}}(p<0.01)$ represents significant at $15 \%$ to $25 \%$ level but not significant at $1 \%$ level

likely to smoke upon the impact of effects of friends/others compared to smokers of ages 35 and above, although it is not statistically significant. It was shown that smokers who were at age 25 to below 35 were 0.473 times less likely to smoke as a result of the influence of friends/others compared to smokers of ages 35 and above. The OR of smokers from ward-7 was $\mathrm{OR}=2.286,95 \%$ CI $0.629-8.312, p>0.01$. Smokers from ward-7 were more likely to smoke as a result of the influence of friends/others compared to smokers from ward-20, although this was not statistically significant. It was shown that smokers from Ward-7 are 2.286 times more likely to smoke as a result of the influence of friends/others compared to smokers from ward-20. The OR of smokers from ward-10 was OR = $2.013,95 \%$ CI $0.441-9.180, p>0.01)$. Smokers from ward10 were more likely to smoke as a result of the influence of friends/others compared to smokers from ward-20, although this was not statistically significant. It was shown that smokers from ward-10 were 2.013 times more likely to smoke as a result of the influence of friends/others compared to smokers from ward-20.

\section{Conclusions}

Smoking in public places should be restricted because nonsmokers cannot breathe freely, and it is not healthy for them to inhale smoke indirectly (passive smoking), which has many adverse effects on public health. In Bangladesh, smokingrelated materials are easily available to children and adolescents, which might encourage experimentation and the subsequent development of a regular smoking habit and ultimately addiction. The majority of respondents learnt smoking from their friends when they were less than 10 years old $(51.3 \%)$. Parents should take the initiative so that their children cannot mix with smoker friends. A significant association exists between smoking creating adverse effects on the social environment and human health and various characteristics of the smoker respondents in the city area. Therefore, further laboratory-based research should be conducte, $\mathrm{d}$ and research should also include non-smoker respondents as a control group for better comparison. Emphasis has to be placed on the legislative authorities making new laws to ban illegal sales of smoking materials to children and also active enforcement of the existing law with regard to smoking in public places. Moreover, in order to curb tobacco usage the authority should take measures such as increasing tobacco taxation, encouraging e-cigarette use, placing a total ban on tobacco advertising and promotion, and also establishing health education campaigns. Finally, an environmental approach needs to be developed to reduce risk factors causing health hazards and to promote comprehensive multi-dimensional protective factors.

Supplementary Information The online version contains supplementary material available at https://doi.org/10.1007/s10389-020-01413-w. 
Acknowledgements The authors would like to acknowledge Dr. Md. Jawadul Hoque, Professor and Dean, Rajshahi Medical University, Bangladesh for his contribution in conceptualization of the study and reviewing the study questionnaire. They would also like to express their sincere gratitude to the study participants who helped us by providing their valuable opinions.

\section{Compliance with ethical standards}

Ethical approval and consent to participate Ethical approval was obtained before collecting data from the Ethical Review Committee of Varendra University, and consent forms were obtained from each respondent before they participated in a face-to-face interview.

\section{Consent for publication Not applicable}

Conflict of interest The authors declare that they have no conflict of interest.

\section{References}

Bangladesh Bureau of Statistics (BBS) (2013) District Statistics 2011 Rajshahi (Population and Housing Census 2011). Bangladesh Bureau of Statistics, Dhaka, p 19

Bellows NM, McMenamin SB, Halpin HA (2007) Adoption of system strategies for tobacco cessation by state Medicaid programs. Med Care 45:350-356

Bush J, White M, Kai J, Rankin J, Bhopal R (2003) Understanding influences on smoking in Bangladeshi and Pakistani adults: community based qualitative study. Br Med J 326:962-965

Cai G, Bossé Y, Xiao F, Kheradmand F, Amos CI (2020) Tobacco smoking increases the lung gene expression of ACE2, the receptor of SARS-CoV-2. Am J Respir Crit Care Med 201(12):1557-1559

Chakraborty N, Islam MA, Chowdhury RI, Bari W, Akhter HH (2003) Determinants of the use of maternal health services in rural Bangladesh. Health Promot Int 18(4):327-337

Cheng T (2014) Chemical evaluation of electronic cigarettes. Tob Control 23(Supplement 2):ii11-ii17. https://doi.org/10.1136/ tobaccocontrol-2013-05148

Coleman T, Barrett S, Wynn A, Wilson A (2003) Comparison of the smoking behaviour and attitudes of smokers who believe they have smoking related problems with those who do not. Fam Pract 20(5): $520-523$

Dhaka Tribune (2019) Govt considering banning e-cigarettes, October 3rd, 2019

Diener-West M (2008) Use of the Chi-Square statistic. Johns Hopkins University, Baltimore, pp 4-19

Dwaidy J, Dwaidy A, Hasan H, Kadry S, Balusamy B (2018) Survey of energy drink consumption and adverse health effects in Lebanon. Health Inf Sci Syst 6:15. https://doi.org/10.1007/s13755-018-0056y

Ezzati M, Lopez AD (2004) Regional disease specific patterns of smoking-attributable mortality in 2000. Tob Control 13:388-395

Ezzati M, Lopez AD, Rodgers A, Vander HS, Murray CJ (2002) Selected major risk factors and global and regional burden of disease. Lancet 360:1347-1360

Faruque GM et al (2019) The economic cost of tobacco in Bangladesh: a health cost approach. Bangladesh Cancer Society, Dhaka

Fiore MC, Bailey WC, Cohen SJ, et al (1996) Smoking cessation clinical practice guideline no. 18. AHCPR publication no. 96-0692. U.S. Department of Health and Human Services, Rockville, MD
Giudice R, Izzo R, Manzi MV, Pagnano G, Santoro M, Rao MA, Renzo GD, Luca ND, Trimarco V (2012) Lifestyle-related risk factors, smoking status and cardiovascular disease. High Blood Press Cardiovasc Prev 19(2):85-92

Global Adult Tobacco Survey (GATS) (2013) Bangladesh report. World Health Organization, Country office for Bangladesh, Dhaka

Global Adult Tobacco Survey (GATS) (2017) Bangladesh report. World Health Organization, Country office for Bangladesh, Dhaka

Islam MI, Khanam R, Kabir E (2020) The use of mental health services by Australian adolescents with mental disorders and suicidality: findings from a nationwide cross-sectional survey. PLoS One 15(4):e0231180

Jarvis MJ (2004) Why people smoke? BMJ 328(7434):277-279

Jha P (2009) Avoidable global cancer deaths and total deaths from smoking. Nat Rev Cancer 9(9):655-664. https://doi.org/10.1038/ $\operatorname{nrc} 2703$

Jones L (2019) Vaping: how popular are e-cigarettes? BBC News, 14 September 2019

Khan MMH, Khan A, Kraemer A, Mori M (2009) Prevalence and correlates of smoking among urban adult men in Bangladesh — slum versus non-slum comparison. BMC Public Health 9:149

Mamun et al (2018) Prevalence and factors associated of cigarette smoking behavior among university male students in Bangladesh: survey in Rajshahi University. J Life Sci 10(1):10-15

Maniruzzaman M, Rahman MJ, Ahammed B, Abedin MM (2020) Classification and prediction of diabetes disease using machine learning paradigm. Health Inf Sci Syst 8:7

Marmot M, Wilkinson R (2006) Social determinants of health, 2nd edn. Oxford University Press, Oxford

Mathers CD, Loncar D (2006) Projections of global mortality and burden of disease from 2002 to 2030. PLoS Med 3:e442

Mokdad AH, Marks JS, Stroup DF, Gerberding JL (2004) Actual causes of death in the United States. J Am Med Assoc 291(10):1238-1245

Mosteller F (1968) Association and estimation in contingency tables. J Am Stat Assoc 63(321):1-28

Mayo Clinic (2020) Nicotine dependence — symptoms \& causes. Mayo Clinic, Rochester, MI. Accessed from https://www.mayoclinic.org/ diseases-conditions/nicotine-dependence/symptoms-causes/syc20351584 on 11 September 2020

Ockene IS, Miller NH (1997) Cigarette smoking, cardiovascular disease, and stroke. A statement for healthcare professionals from the American Heart Association. Circulation 96(9):3243-3247

Picciotto MR, Kenny PJ (2013) Molecular mechanisms underlying behaviors related to nicotine addiction (2013). Cold Spring Harbor Perspect Med 3(1):a012112

Rothemich SF, Woolf SH, Johnson RE, Burgett AE, Flores SK, Marsland DW, Ahluwalia JS (2008) Effect on cessation counseling of documenting smoking status as a routine vital sign: an ACORN study. Ann Fam Med 6:60-68

Sadeghi R, Scriven A, Garman S (2011) The influence of social environment on smoking behavior among adolescents in Iran. Med J Islam Repub Iran 25(2):66-75

Schraufnagel DE, Blasi F, Drummond MB, Lam DCL, Latif E, Rosen MJ, Sansores R, Van Zyl-Smit R (2014) Electronic cigarettes: a position statement of the forum of international respiratory societies. Am J Respir Crit Care Med 190 (6):611-618

Simons D, Shabab L, Brown J, Perski O (2020) The association of smoking status with SARS-CoV-2 infection, hospitalisation and mortality from COVID-19: a living rapid evidence review (version 4). Qeios ID: UJR2AW.5. https://doi.org/10.32388/UJR2AW.5

Survey System (2020) Survey software - the Survey System. Accessed from https://www.surveysystem.com

Thompson B, Thompson LA, Thompson J, Fredickson C, Bishop S (2003) Heavy smokers: a qualitative analysis of attitudes and beliefs concerning cessation and continued smoking. Nicotine Tob Res 5: 923-933 
U.S. Department of Health and Human Services Report (2004) The health consequences of smoking: a report of the surgeon general. U.S. Department of Health and Human Services, Centers for Disease Control and Prevention, National Center for Chronic Disease Prevention and Health Promotion, Office on Smoking and Health, Atlanta

U.S. Department of Health and Human Services Report (2010) How tobacco smoke causes disease: what it means to you. U.S. Department of Health and Human Services, Centers for Disease Control and Prevention, National Center for Chronic Disease Prevention and Health Promotion, Office on Smoking and Health, Atlanta

U.S. Department of Health and Human Services Report (2020) Smoking cessation. A report of the surgeon general. U.S. Department of Health and Human Services, Centers for Disease Control and Prevention, National Center for Chronic Disease Prevention and Health Promotion, Office on Smoking and Health, Atlanta. https:// www.hhs.gov/sites/default/files/2020-cessation-sgr-full-report.pdf

Vogt F, Hall S, Marteau TM (2008) Understanding why smokers do not want to use nicotine dependence medications to stop smoking: qualitative and quantitative studies. Nicotine Tob Res 10:1405-1413

Wahed WYA, Hassan SK (2017) Prevalence and associated factors of stress, anxiety and depression among medical Fayoum University students. Alexandria J Med 53(1):77-84. https://doi.org/10.1016/j. ajme.2016.01.005

Wang C, Xu J, Yang L, Xu Y, Zhang X, Bai C et al (2018) Prevalence and risk factors of chronic obstructive pulmonary disease in China (the China Pulmonary Health [CPH] study): a national crosssectional study. Lancet. 391(10131):1706-1717

WHO (2003) Tobacco Free Initiative (TFI). WHO, Geneva. Accessed from https://www.who.int/tobacco/resources/publications/tobacco dependence/en/

WHO Expert Consultation (2004) Appropriate body-mass index for Asian populations and its implications for policy and intervention strategies. Lancet 363(9403):157-163

World Bank (1999) Curbing the epidemic: governments and the economics of tobacco control. World Bank, Washington DC

World Health Organization (2005) Impact of tobacco-related illnesses in Bangladesh, Dhaka. WHO, Geneva

Yen IH, Syme SL (1999) The social environment and health: a discussion of the epidemiologic literature. Annu Rev Public Health 20:287-308

Publisher's note Springer Nature remains neutral with regard to jurisdictional claims in published maps and institutional affiliations. 